\title{
Modeling of the torsion test of a cylindrical specimen with the help of the inverse method
}

\author{
D.O. Shishkin, P.A. Petrov \\ Department of Materials Processing by Pressure and Additive Technologies, Faculty of Mechanical \\ Engineering, Moscow Polytechnic University, Moscow, Russia
}

\begin{abstract}
This article discusses the torsion problem of a continuous cylindrical specimen used to construct a hardening curve. A brief review of the methods for processing the results of the method of torsion of a cylindrical specimen is given. The possibility of using the inverse method to determine the material model in the case of the torsion of the continuous cylindrical specimen made of steel $20 \mathrm{H}$ is shown. By means of QFORM 9.0 software package virtual experiment connected with torsion of a cylindrical specimen is carried out. As a result of this research, the rheological model of steel $20 \mathrm{His}$ determined with a high degree of accuracy. The stress-strain state of the material was analyzed during the torsion of the specimen by means of the QFORM. The results of the virtual experiment are compared with the full-scale test.Anexceptionally good match of the results was obtained. The inverse method showed its efficiency and made it possibleto determine a rheological model of the material. The model accurately describes the experimental data. The resulting material model (for steel $20 \mathrm{H}$ ) is valid in the following range of parameters: deformation temperature of $20^{\circ} \mathrm{C}$, deformation rate of $0.5 \mathrm{~s}^{-1}$, the strain range of 0 to 2.5 .
\end{abstract}

\section{Introduction}

The method of testing materials by torsion has been known since 1930. The torsion method has found its application in studying the technological properties of materials under cold and hot deformation; it is used to obtain a hardening curve (flow), which is the basis for constructing rheological model of the material [1].

Currently, several versions of the implementation of the torsion method are known: the method of torsion of a tubular sample, the method of torsion of a continuous cylindrical sample, the method of torsion of a conventionally tubular sample. The use of continuous cylindrical samples instead of tubular ones allows for larger deformation. However, the torsion of cylindrical samples has several drawbacks: uneven distribution of deformations along the radius and length of the sample, which, in its turn, varies with time; the possibility of propagation of deformation on the fillet of the sample, which may affect the angle of its 
twisting. Localization of strains during torsion of continuous cylindrical samples is also possible.

The torsion results of the torsion test experiments can be processed using one of the following methods: the Nadai graphical method [2], the Fields and Bekofen method [3], the Khoddam method[4], and the inverse method [5]. The most reliable method is the inverse method since it allows to take into account the disadvantages inherited during the processing of the test results mentioned above. The inverse method provides a high degree of accuracy to explicitly determine the material model [6,7]. At the same time, the simplifying assumptions accepted for the processing of the results of experimental studies (the torsion method, the compression method, the tensile method) could be neglected when a material model is determined with the help of the inversetechnique.This work aims to conduct finite element modeling of torsion of a continuous cylindrical specimen made of steel 20H (GOST 4543-2016). The problem to be solved is the determination of the rheological model of the material under study and the construction of the hardening curve of steel $20 \mathrm{H}$.

\section{Description of experiment}

The torsion test of a continuous cylindrical specimen is used in this paper to explicitly determine the rheological model of a deformable material. Processing of the results of the experiment on torsion of a cylindrical sample is carried out with the QFORM 9.0 software package using the inverse method. The shape of the cylindrical sample is shown in Figure 1.

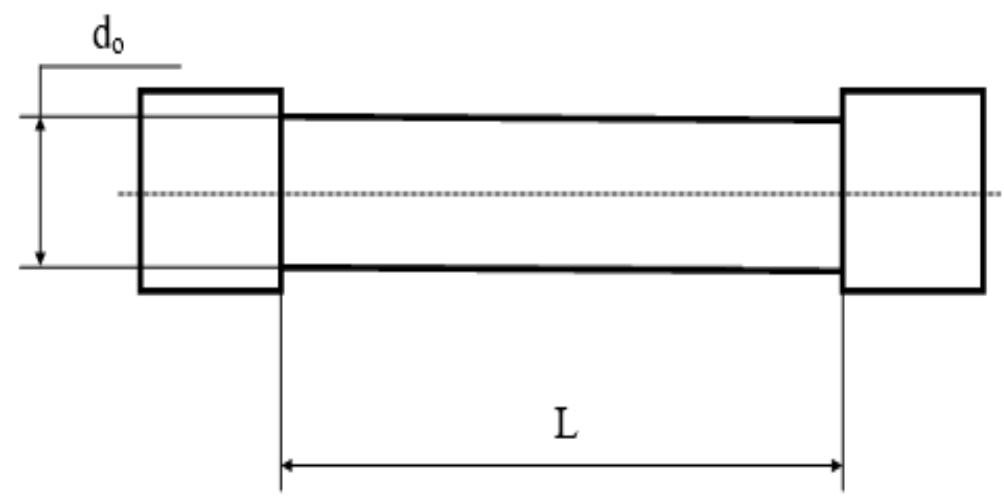

Fig. 1.Cylindrical specimen for the torsion

The dimensions of the cylindrical specimen are presented in Table 1.

Table 1. Sizes of the cylindrical specimen

\begin{tabular}{cc}
\hline Parameter & Value of parameter \\
\hline Diameter $d_{0}, \mathrm{~mm}$ & $10.00 \pm 0.1$ \\
Length $L, \mathrm{~mm}$ & $77.4 \pm 0.5$ \\
Roughness of the & Ra 1.25 \\
specimen's surface & \\
\hline
\end{tabular}


The chemical composition in accordance with GOST 4543-2016 is presented in Table 2:

Table 2. Chemical composition of the steel $20 \mathrm{H}$.

\begin{tabular}{cc}
\hline $\begin{array}{c}\text { Chemical element } \\
\text { concentration, } \%\end{array}$ & Value \\
\hline $\mathrm{C}$ & $0.17-0.23$ \\
$\mathrm{Si}$ & $0.17-0.37$ \\
$\mathrm{Mn}$ & $0.5-0.8$ \\
$\mathrm{Ni}$ & up to 0.3 \\
$\mathrm{~S}$ & up to 0.035 \\
$\mathrm{P}$ & up to 0.035 \\
$\mathrm{Cr}$ & $0.7-1$ \\
$\mathrm{Cu}$ & up to 0.3 \\
\hline
\end{tabular}
2 .

The scheme of the inverse method technique applied in this paper is presented in Figure

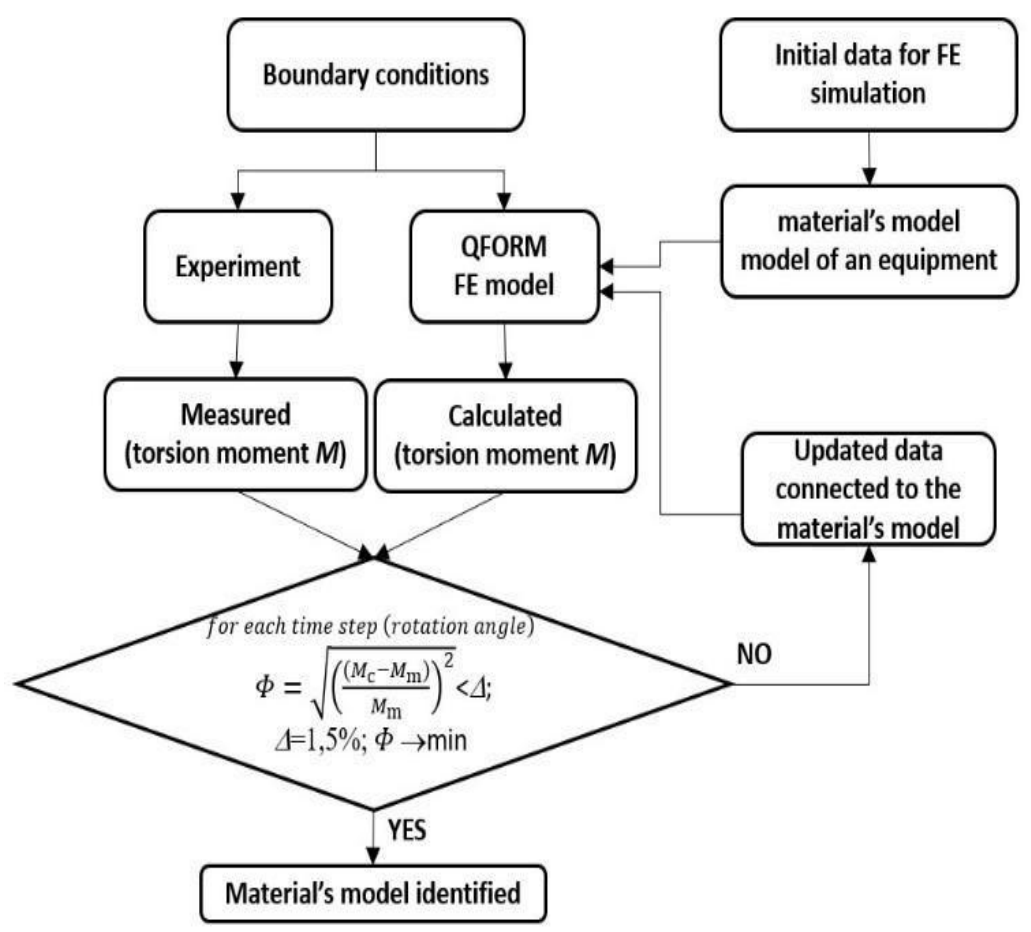

Fig. 2.Scheme of the inverse method technique

The objective function $\Phi$ is formed for each time step of a virtual experiment [8]. The rotation angle $\theta$ corresponds to a certain time step. The calculation is considered complete if the value of the objective function reaches the minimum value within the threshold deviation $\Delta=1.5 \%$. As a result of the implementation of the inverse method scheme, a 
rheological model can be determined for steel $20 \mathrm{H}$.

\section{Finite element modeling of torsion of a cylindrical specimen}

QForm 9.0 is based on the flow theory. A detailed description of the program is presented in [9]. The material of the specimens is steel 20H (Russian standard GOST 4543-2016), similar to AISI $5120 \mathrm{H}$ or DIN 20CrS4. This paper considers the cold plastic deformation of the steel sample during torsion; in general, a material model can be represented as a function of one variable:

$$
\sigma_{s}=f(\varepsilon) \sigma_{s}=f(\varepsilon)
$$

The model given by Eq. 1 was taken from the standard QFORM material database as the set of the flow stress-strain curves in tabular form for temperature $T=20^{\circ} \mathrm{C}$, strain rate $\varepsilon$ $=0.5 \mathrm{~s}^{-1}$ and for a range of strain intensities $\varepsilon €[0.0-2.5]$. Further, the model is refined based on the implementation of the inverse method scheme(Fig. 2).

The finite element model of the sample for virtual torsion testing using QForm 9.0 is shown in Figure 3. The initial finite element model of the cylindrical sample includes 33924 finite elements and 7713 nodes. This model is used to determine the rheological model based on the implementation of the inverse method (Fig. 2).

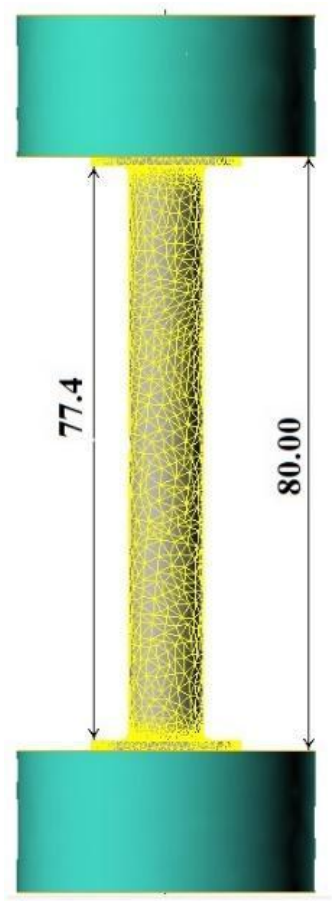

Fig.3. A finite-element model of torsion of the cylindrical specimen

Input data for the finite-element modeling of torsion of a cylindrical specimen:

- Length (initial) of the work piece $(L)$ is $77.4 \mathrm{~mm}$.

- Diameter (initial) of the work piece $\left(d_{0}\right)$ is $10.0 \mathrm{~mm}$. 
- Friction factor $(m)$ :no lubrication is provided.

- Temperature (initial) of the work piece $\left(t_{0 \mathrm{w}}\right)$ is $20^{\circ} \mathrm{C}$.

- Temperature (initial) of tools $\left(t_{0 \text { tool }}\right)$ is $20^{\circ} \mathrm{C}$.

- Temperature (initial) of ambient media $\left(t_{0 \mathrm{amb}}\right)$ is $20^{\circ} \mathrm{C}$.

- Angular velocity $(\omega)$ of upper tool rotation is $60 \mathrm{rpm}$.

- The lower tool is fixed and stationary.

- The heat effect of plastic deformation as well as friction is neglected.

\section{Results and discussion}

The torsion test of a cylindrical sample is characterized by the flow of material in the circumferential direction due to shear (Fig. 4a). The distribution of the strain intensity in the cross-section of a cylindrical sample has a slight non-uniformity (Fig. 4b). The minimum value of the strain intensity is achieved in the centre of the sample (see Fig. 4b), while the maximum (0.6563) is achieved on the lateral surface of the working part of the cylindrical sample. The result obtained agrees with the known observations of the material behaviour of the cylindrical sample $[2,10]$. The disadvantage of this test is the in homogeneity of the material flow in the cross-section of the cylindrical sample is a .

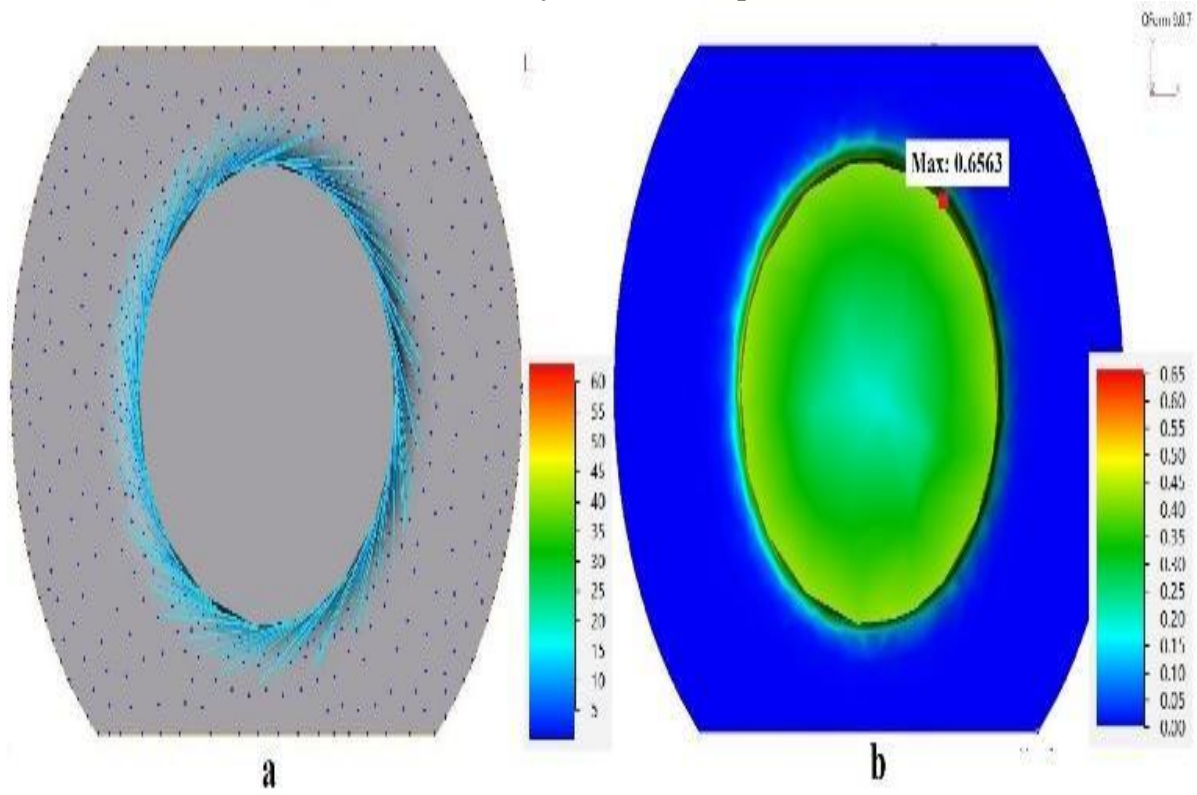

Fig.4.Material flow during the cylindrical specimen torsion: (a) distribution of the velocity vector (in $\mathrm{mm} / \mathrm{s}$ ); (b) distribution of the effective strain

In the longitudinal direction, the material flow is also non-uniform (see Fig. 5a). The effective stress has the maximum value in the area near the thickening for clamping (see Fig. 5a). The localization of strain results in the rapture of the cylindrical specimen (Fig. 6). 


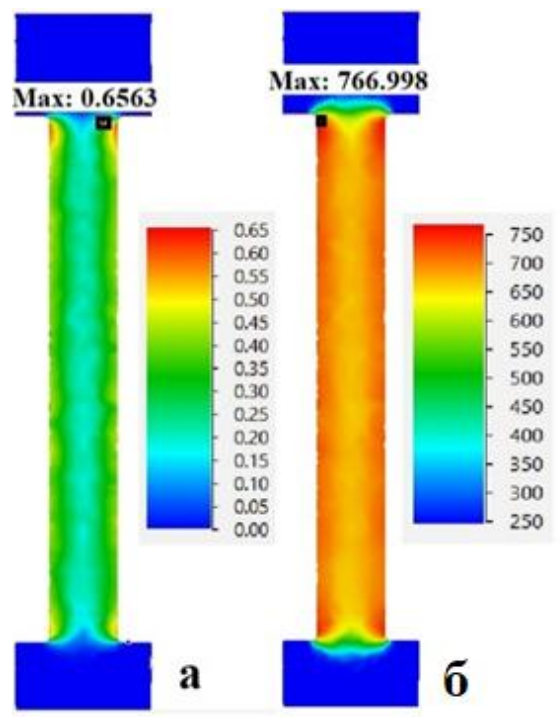

\begin{tabular}{c|c}
\hline $\begin{array}{c}\text { Effective } \\
\text { strain }\end{array}$ & $\begin{array}{c}\text { Effective } \\
\text { stress, MPa }\end{array}$ \\
\hline 0.005 & 246.00 \\
0.0998 & 586.67 \\
0.2997 & 684.93 \\
0.4992 & 746.40 \\
0.8007 & 799.35 \\
1.2006 & 834.85 \\
1.8018 & 863.64 \\
2.5010 & 884.44 \\
\hline
\end{tabular}

B

Fig. 5.Distribution of the stress and strain in the longitudinal section of the cylindrical specimen: (a) distribution of the effective strain; (b) distribution of the effective stress (in MPa); (c) the flow stressstrain curve.

The flow stress-strain curve (see Fig. 5c) was approximated by the function which is similar to the Hensel-Spittel equation [10] but has a free term that takes into account that the plastic flow starts from the yield strength value:

$$
\begin{gathered}
\sigma_{s}=A+B \varepsilon_{i_{1}}^{m_{1}} e^{\left(m_{2} / s_{i}\right)} \\
\sigma_{s}=A+B \varepsilon_{i} e^{\left(m_{2} / \varepsilon_{i}\right)}
\end{gathered}
$$

The unknown coefficients in Equation (2) were identified using the LevenbergMarquardt method implemented in Matlab. The value of standard deviation $R^{2}$ is given in Table 3.

Table 3. Coefficients of equation (2)

\begin{tabular}{ccccc}
\hline$A, \mathrm{MPa}$ & $B, \mathrm{MPa}$ & $m_{1}$ & $m_{2}$ & $R^{2}$ \\
\hline 246.00 & 595.00 & 0.099 & -0.05 & 0.977 \\
\hline
\end{tabular}



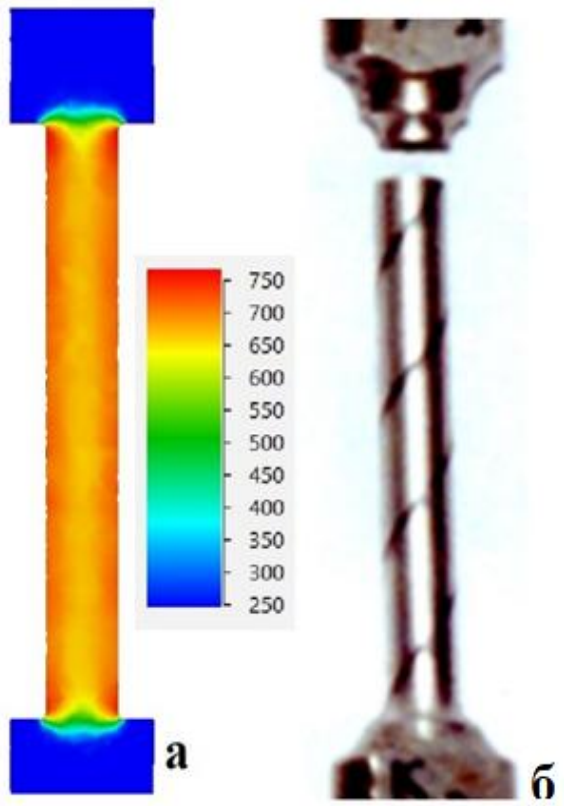

Fig.6.Comparison between the shape of the FE model (a) and the full-scale specimen (b)

Figure 7 shows the comparison of the results. The reference line, i.e., $\sigma_{\mathrm{se}}=\sigma_{\mathrm{sp}}$, implies the ideal regression result for the deformation condition under this study. The data are spread around the reference line.

The data points are close to the reference line and the model chosen for calculation of the coefficients show no systematic deviations in the prediction from them besides one point only. The chosen model (see Equation (2) and Table (3)) gives good consistency for the cold deformation condition in the case of the torsion of the cylindrical specimen made of steel $20 \mathrm{H}$.

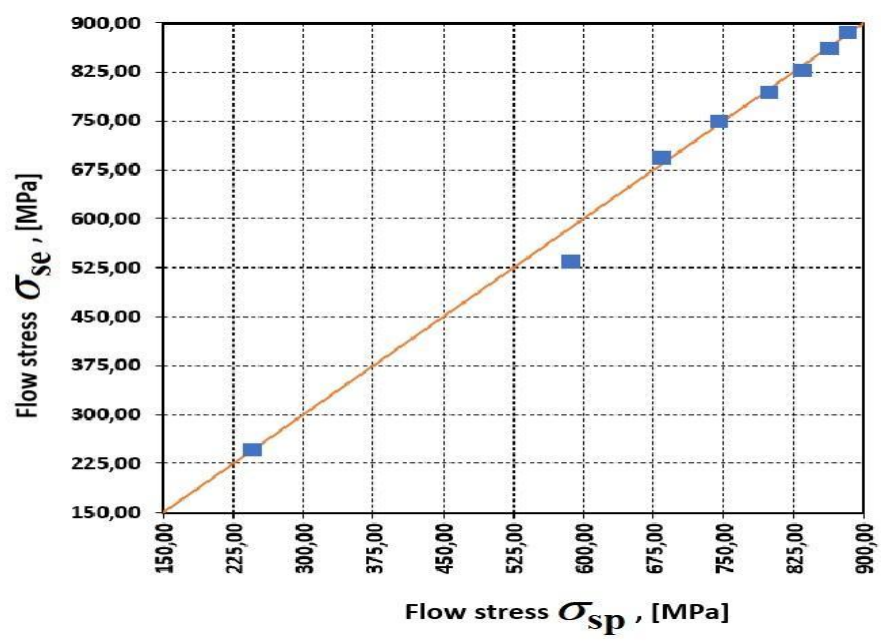

Fig. 7.Comparison of the results obtained with the help of inverse technique based on the experimental data (index e) with the values of the model's parameters (index p) 
After defining the rheological model, the comparative evaluation of the hardening curve was performed based on the obtained curve with the help of the classical method suggested by P. Ludwik [11] and the hardening curve obtained with the help of equation (2). The results of the comparative evaluation are presented in Figure 8.

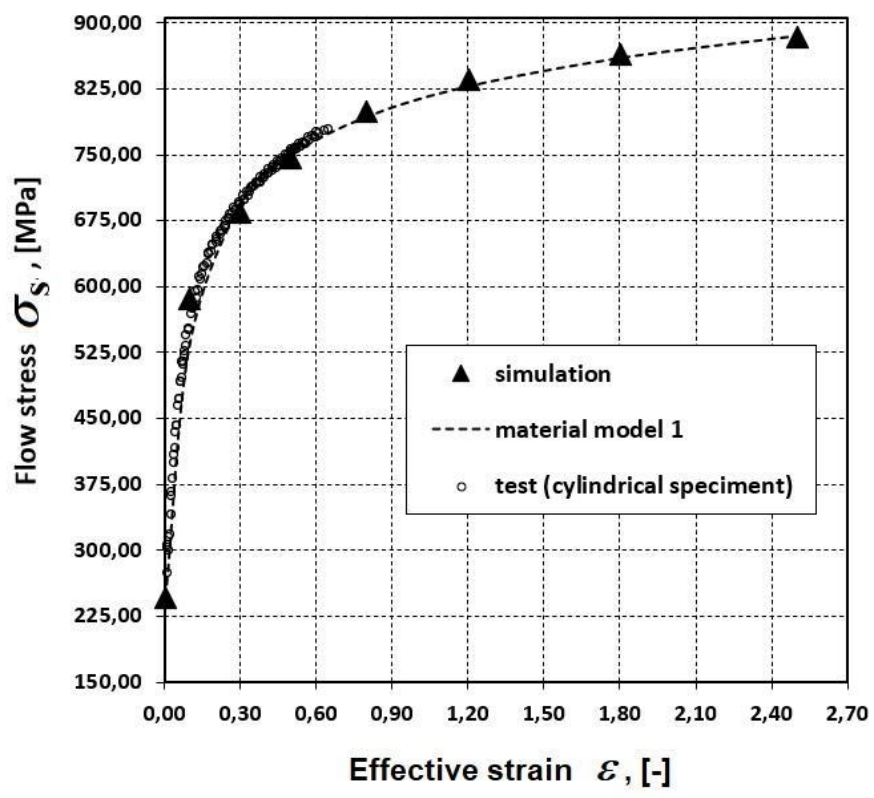

Fig.8.Torsion of the cylindrical specimen: experimental data (open circles) vs. FE simulation results (black triangles)

The material model (dash line; see Fig.8) is in good agreement with the experimental results, as well as the results of the FE modeling. The accuracy of the FE modeling was proven by the comparative evaluation of the experimental values of the torsion moment and the results of the FE simulation of torsion of the cylindrical specimen (Fig. 9). 


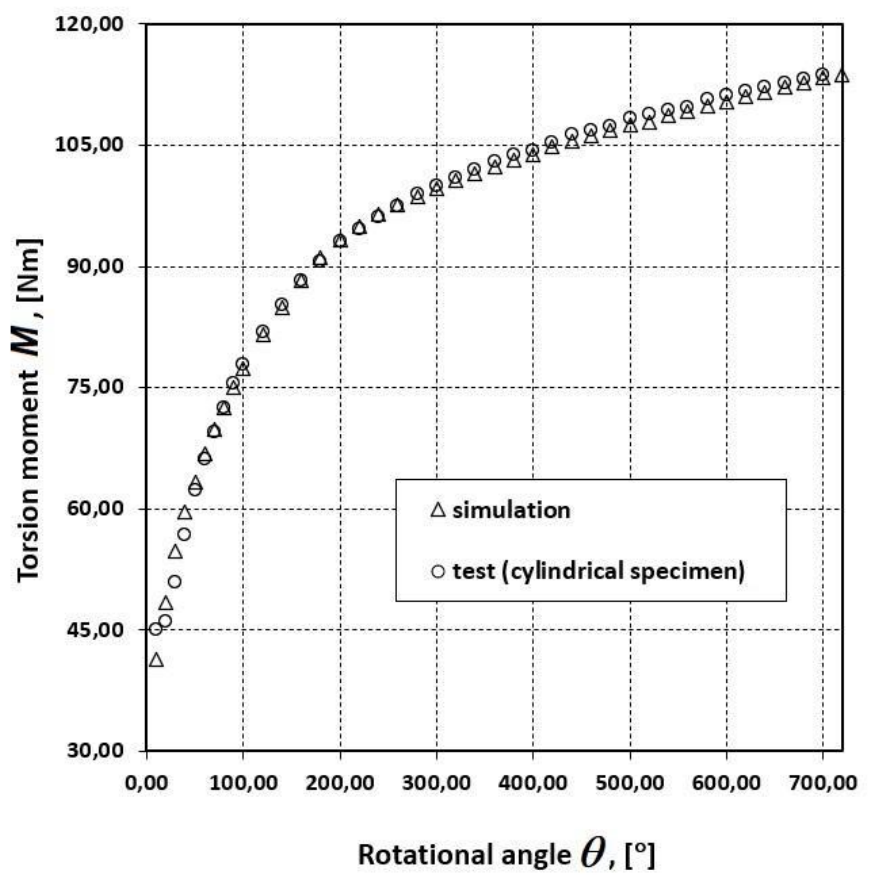

Fig. 9.Torsion moment vs. rotational angle for torsion of the cylindrical specimen

The stress-strain curve is experimentally obtained within the effective strain range of 0.0-0.7.(see Fig.9). The material model accurately describes the behavior of the deformable material within a given range of strain values. Therefore, an assumption was made about the possibility of extrapolating the calculation results from the model found outside the domain of determination of the strain intensity. Figure 8 shows the results of extrapolation (dashed line). This approach allows a more accurate description of the current stress, overcome the assumptions of the programs based on the finite element method [9] and, therefore, increase the accuracy of the stress calculations.

\section{Conclusions}

Ananalysis of material flow during torsion of a cylindrical sample was performed using the QFORM program. The results of a virtual experiment are compared with the results of the full-scale experiment. An exceptionally good match of the results is obtained.

The inverse method showed its efficiency and allowed to determine the rheological model of the material. The model accurately describes the experimental data. The resulting material model (for steel $20 \mathrm{H}$ ) is valid within the following range of parameters: the deformation temperature of $20^{\circ} \mathrm{C}$, the strain rate of $0.5 \mathrm{~s}^{-1}$, the strain rangefrom 0 to 2.5.

\section{References}

1. A.Sauveur, Steel at elevated temperatures.(Trans. Am. Soc. Steel Treating 1930).

2. A.Nadai, Theory of Flow and Fracture of solids.(New York: McGraw-Hill 1950). 
3. D.F. Fields, W.A. Backofen, Determination of strain-hardening characteristics by torsion testing. American Society for Testing and Materials, Proceedings of the Sixtieth Annual Meeting of the Society, 57, 1259-1272 (1957).

4. S. Khoddam, P. Hodgson, Post Processing of the Hot Torsion Test Result Using a Multi-Dimensional Modelling Approach, Material and Design, 31, 2578-2584 (2010).

5. E. Massoni, R. Forestier, et al Inverse analysis for the identification of thermal and mechanical parameters of materials. In: M. Pietrzyk editor. Fifth ESAFORM Conference on Material Forming. Krakow, 159-162 (2002).

6. K.E. Potapenko, V.I. Voronkov, P.A. Petrov Determination of the rheological model based on the isothermal flow curves, Zagotovitelnye proizvodstva $v$ mashinostroenii (forging, foundry and other industries),8, 32-38 (2013).

7. K.P. Rao, Y.K.D.V. Prasad, E.B. Hawbolt, An algorithm for flow stress determination under varying process conditions, Journal of Materials Processing Technology, 56, 908-917 (1996).

8. D.Szeliga, M.Pietrzyk Identification of Rheological and Tribological Parameters. In: Metal Forming Science and Practice, ed., Lenard J.G.(Amsterdam: Elsevier, 2002).

9. Plastic deformation of materials. QForm 2D / 3D User Guide. Program for modeling metal forming processes. Part 4. Theoretical foundations of QForm.(Moscow: LLC QuantorForm, 2017).

10. A.Hensel, T.Spittel Calculating of power parameters in the processes of metal forming: trans.(Germany, M: Metallugriya, 1982).

11. S.I. Gubkin Plastic deformation of metals.(M.: Metallurgizdat,1961). 